\title{
An Econometric Analysis of Consumer's Willingness to Buy Locally Produced Wine: A Study in the Mid-Atlantic U.S.
}

\author{
Ramu Govindasamy ${ }^{1}$, Surendran Arumugam ${ }^{2}$, Jingkun Zhuang ${ }^{1}$, Kathleen M. Kelley ${ }^{3}$ \\ and Isaac Vellangany ${ }^{1}$
}

\begin{abstract}
${ }^{1}$ Department of Agricultural, Food and Resource Economics, Rutgers - The State University of New Jersey ${ }^{2}$ Imayam Institute of Agriculture \& Technology, Thuraiyur, Tiruchirappalli, Tamil Nadu, India ${ }^{3}$ Department of Horticulture, The Pennsylvania State University, USA

*Corresponding authors: govind@sebs.rutgers.edu
\end{abstract}

\begin{abstract}
US wine sales approached $\$ 60$ billion in 2016, of which, an estimated $\$ 39.8$ billion was generated from domestic wine sales and the remainder from imports. On average, 120 million Americans, age 21 and older, drink wine, which is approximately $36 \%$ of total population (330 million). Wine consumer demographic characteristics play a significant role in the wine consumption decisions. Results from a logit regression show that the following groups more likely to buy local wine than their counterparts for example: New York residents; consumers between 45 and 64 years of age old; males; those with annual household incomes between $\$ 76,000$ and $\$ 200,000$; participants with a bachelor's degree or higher; those who drink wine once a week or two to three times a week; those who purchase wine to consume during different occasions; those who purchase wine for everyday purposes to be consumed in their home; those who purchase wine to be added to their collections or to be consumed at a later time are more likely to buy local wine; those who often drink wine with food, when at a social gathering with family and friends, or at the end of the day to relax, are more likely to purchase local wine. The assessment of consumers' willingness to buy locally produced wine will help producers, wholesalers, and retailers target likely buyers based on segments.
\end{abstract}

Keywords: Wine, Purchase Behavior, Consumer Behavior, Logistic Regression, Marketing Strategy, Decision Making, Mid-Atlantic

Wine consumption, by volume, in the United States (US) has increased from 163 million gallons in 1960 to 913 million gallons in 2015 (Wine Institute, 2017). In 2015 alone, 327 million cases, an increase of $0.2 \%$ over the previous year, of this beverage were consumed (Shanken News Daily, 2015). According to a Wine Institute report (2015), Americans consumed 893 million gallons of wine in 2014 (2.8 gallons per consumer, up from 568 million gallons in 2000 (2.01 gallons per resident). Of the total 2015 US wine sales, approximately $73 \%$ represented domestic wines (mainly California) (Nielsen report, 2017). Of the $27 \%$ of wine that was imported, several countries including Italy, France, Chile, Spain, Argentina, and New Zealand reported gains in the US market. In more recent years, groups of foreign wineries have joined forces to implement more concerted efforts to market their wine in the US (Wines of Province, 2016). With 10\% increase in consumption of imported wine between 2011 and 2015 , one would expect that foreign winery groups will continue to target US wine consumers (Wines of Province, 2016).

As of June 2016, there were 8,862 wineries in the US (U.S. Winery Database, 2016). which is a sharp increase from the 2,688 that existed in 1999 (Fisher, 2011). Of the nearly 9,000 wineries in the US, $7 \%$ are in three Mid-Atlantic States: New Jersey (52 in June 2016), New York (367 in June 2016), and Pennsylvania (220 in June 2016). Though the total number of wineries in Mid-Atlantic area is relatively small compared to other regions in the US, growth 
in terms of number of wineries has matched that of the US in New York, ranked $4^{\text {th }}$ out of the 50 states in term of the number of wineries, with Pennsylvania ranking $7^{\text {th }}$, and New Jersey ranking $20^{\text {th }}$ (U.S. Winery Database, 2016). Grape and wine production in these states represents a significant share of the total amount produced in the country. New York and Pennsylvania ranked $3^{\text {rd }}$ and $7^{\text {th }}$ (Whetstone et al. 2011). Respectively, in wine grape production by the end of 2010, bulk wine production in these three states was just under $4 \%$ of total US production, with New York producing 93\% of the total for the three Mid-Atlantic States. Hence, it is important to develop new wine marketing strategy in this region to meet consumer expectations.

The demographic characteristics that describe wine consumers are considered to play a significant role in the wine consumption decisions (Dodd, Laverie, Wilcox, \& Duhan, 2005; Brager, 2014; Janeen et al. 2015). Mostly, understanding consumer behavior in the context of the US market is essential, as the US has accounted for the most significant volume of wine sales since 2010 (Wine Institute, 2014). In this context, Consumers' willingness-to-pay (WTP) and willingness-to-buy (WTB) studies are often used in determining market potentials (Govindasamy et al. 2015; Govindasamy et al. 2014; Surendran and Sekar 2010; Arumugam, 2017). Likewise, wine suppliers need to better understand their customers' wine attitudes and behaviors, something they may not examined in detail in the past. Obtaining answers to questions such as occasions for which wine is purchased and consumed, varietal preferences, purchasing frequency, drinking frequency and so forth will better assist stakeholders with developing appropriate products and applicable marketing strategies. Against this background, this study has attempted to predict the factors (e.g., purchasing behavior and attitudes and socio-demographic attributes) that influence consumers' willingness to buy local wine.

This study also focused on predicting the relationship between ethnic product attributes and the willingness to buy locally produced wine. Study findings may provide a better understanding of wine consumers' purchasing behavior to support local wine producers in the mid-Atlantic United States.

\section{DATA AND METHODOLOGY}

A 15-minute internet survey administered to Survey Sampling International, LLC (Shelton, CT) panelists residing in three states (New Jersey, New York, and Pennsylvania) in the Mid-Atlantic region of the USA in 2009. Panelists were screened for not being a member of the wine industry, being at least 21 years old, residing in one of the targeted states, and for having purchased and drank wine at least once within the previous year. Panelists were informed of these criteria in an electronic consent statement prior to proceeding with the survey. Those who qualified were directed to the survey which was developed by the researchers and administered using an online provider of survey solutions.

This survey helped to quantify consumer wine purchases and preferred varieties, identify the demographics and behaviors that describe midAtlantic wine buyers to assist small and mediumsized farmers with better understanding these consumer's perceptions and preferences for midAtlantic wines. The Office of Research Protections at The Pennsylvania State University (University Park, PA) and the Office of Research and Sponsored Programs, Rutgers-The State University of New Jersey (New Brunswick, NJ) approved the survey instrument. The survey was pre-tested on a subset of the target consumer population, with a total of 1,246 responses obtained. Participants received $\$ 1.00$ incentive for completing the survey.

\section{MODEL FRAMEWORK}

Sample respondents were asked if they purchased local wine, of which 613 indicated they purchased local wine and 633 responded that they did not. In the logit model design, the response variable is defined as ' 1 ' if the sample respondent purchased local wine (BUY) and '0' otherwise. The logit model assumes that the chance of observing the response variable $(\mathrm{Pi})$ is contingent upon a vector of explanatory variables (Xij) associated with the consumer (i) and variable (j). The relationship between the buyer of local wine and consumers' purchasing behavior, and socio-demographic characteristics were expressed as follows:

$$
P_{i}=F\left(\beta_{J} \chi_{i j}+\varepsilon\right)
$$

$=\beta_{0}+\beta_{1}$ purchasing behavior of consumers 
$+\beta_{2}$ Wine attributes

$+\beta_{3}$ Socio-demographic characteristics $+\varepsilon$

Where:

$P_{i}$ is the probability of buying local wine,

$\beta_{J} \chi_{i j}$ is the explanatory variables

$\beta$ is the parameters to be estimated, and

$\varepsilon$ is an error term.

The logistic distributional assumption for the random term, the probability $P_{i}$ can be expressed as:

$$
\begin{aligned}
& P_{i}=F\left(\beta_{0}+\sum_{j=1}^{j} \beta_{j} \chi_{i j}\right)=F\left(\beta \chi_{i}\right)= \\
& 1 /\left[1+\exp \left(-\beta \chi_{i}\right)\right]
\end{aligned}
$$

The estimated coefficients of probability function (Equation 2) do not directly denote marginal effects (ME) of the explanatory variables on the probability $P_{i}$.

If the response variable is continuous, the marginal effect of $\chi_{i}$ on $P_{i}$ is given equation (3):

$$
\partial P_{i} / \partial \chi_{i j}=\left[\beta_{j} \exp \left(-\beta \chi_{i}\right)\right] /\left[1+\exp \left(-\beta \chi_{i}\right)\right]^{2}
$$

Whereas, for a binary explanatory variable $\chi_{i j^{\prime}}$ that takes values of 1 or 0 , the marginal effect is determined as per equation (4):

$$
\partial P_{i} / \partial \chi_{i j}=\left[P\left(\chi_{i j}=1\right)-P\left(\chi_{i j}=0\right)\right] /[1-0]
$$

The Logit model is framed as equation (5)

Below is how the logistic regression model was specified.

$$
\begin{aligned}
\operatorname{logit}\left(p_{\text {buy }}\right)= & \log \left(\frac{p_{\text {buy }}}{1-p_{\text {buy }}}\right) \\
& =\beta_{0}+\beta_{1} \text { stateNY }+\beta_{2} \text { statePA } \\
& +\beta_{3} \text { age } 45 \text { to } 64+\beta_{4} Q 1 a_{2}+\beta_{5} Q 1 a_{3} \\
& +\beta_{6} Q 1 a_{4}+\beta_{7} Q 1 a_{5}+\beta_{8} Q 1 a_{6}+\beta_{9} Q 3 b \\
& +\beta_{10} Q 3 e+\beta_{11} Q 4 a+\beta_{12} Q 4 b+\beta_{13} Q 4 c \\
& +\beta_{14} Q 7_{1}+\beta_{15} Q 7_{3}+\beta_{16} Q 7_{4}+\beta_{17} Q 75 \\
& +\beta_{18} Q 11 a+\beta_{19} Q 11 b+\beta_{20} Q 11 c \\
& +\beta_{21} Q 11 d+\beta_{22} Q 11 e+\beta_{23} Q 11 i \\
& +\beta_{24} Q 15+\beta_{25}{\text { gender }+\beta_{26} \text { educ }} \text { ed } \\
& +\beta_{27} \text { fam }_{\text {inc } 1}+\beta_{28} \text { fam }_{\text {inc }}+\beta_{29} \text { job }_{2} \\
& +\beta_{30} \text { job }_{3}+\beta_{31} \text { job }_{4}+\beta_{32} \text { job }_{5}+\beta_{33} \text { job }_{6} \\
& +\beta_{34} \text { marital }_{2}+\beta_{35} \text { marital }_{3} \\
& +\beta_{36} \text { marital }_{4}
\end{aligned}
$$

\begin{tabular}{|c|c|}
\hline Variable & Particulars \\
\hline \multicolumn{2}{|r|}{ Dependent variables } \\
\hline BUY_Local & $\begin{array}{l}1 \text { if the respondents willing to buy locally } \\
\text { produced Wine; } 0 \text { Otherwise; }\end{array}$ \\
\hline \multicolumn{2}{|r|}{ Independent variables } \\
\hline state NY & $\begin{array}{l}1 \text { if the respondent's residence in NY; } 0 \\
\text { Otherwise }\end{array}$ \\
\hline state PA & $\begin{array}{l}1 \text { if the respondent's residence in PA; } 0 \\
\text { Otherwise }\end{array}$ \\
\hline $\begin{array}{l}\text { Age } 45 \text { to } \\
64\end{array}$ & $\begin{array}{l}1 \text { if the respondent's age between } 45 \text { to } 64 ; \\
0 \text { Otherwise }\end{array}$ \\
\hline Q1a_F2 & $\begin{array}{l}1 \text { if the respondent consumes wine a few } \\
\text { times a week; } 0 \text { Otherwise }\end{array}$ \\
\hline Q1a_F3 & $\begin{array}{l}1 \text { if the respondent consumes wine about } \\
\text { once a week; } 0 \text { Otherwise }\end{array}$ \\
\hline Q1a_F4 & $\begin{array}{l}1 \text { if the respondent consumes wine } 2 \text { to } 3 \\
\text { times a month; } 0 \text { Otherwise }\end{array}$ \\
\hline Q1a_F5 & $\begin{array}{l}1 \text { if the respondent consumes wine about } \\
\text { once a month; } 0 \text { Otherwise }\end{array}$ \\
\hline Q1a_F6 & $\begin{array}{l}1 \text { if the respondent consumes wine a few } \\
\text { times a year; } 0 \text { Otherwise }\end{array}$ \\
\hline Q3b & $\begin{array}{l}1 \text { if the respondent purchases the } \\
\text { "everyday" wine that they consume in the } \\
\text { home during an average day; } 0 \text { Otherwise. }\end{array}$ \\
\hline Q3e & $\begin{array}{l}1 \text { if the respondent selects the wine from } \\
\text { the menu at a restaurant; } 0 \text { Otherwise. }\end{array}$ \\
\hline Q4a & $\begin{array}{l}1 \text { if the respondent typically purchases } \\
\text { one or more } 750 \mathrm{ml} \text { bottles to be consumed } \\
\text { immediately; } 0 \text { Otherwise }\end{array}$ \\
\hline Q4b & $\begin{array}{l}1 \text { if the respondent typically purchases } \\
\text { one or more bottles to be added to their } \\
\text { collection and/or be consumed at a later } \\
\text { time; } 0 \text { Otherwise }\end{array}$ \\
\hline Q4c & $\begin{array}{l}1 \text { if the respondent purchases wine } \\
\text { infrequently, but when they do they } \\
\text { purchase at least a case ( } 12 \text { or more } 750 \mathrm{ml} \\
\text { bottles); } 0 \text { Otherwise }\end{array}$ \\
\hline Q7_1new1 & $\begin{array}{l}1 \text { if the respondent is willing to pay more } \\
\text { for everyday wine or special occasion; } 0 \\
\text { Otherwise }\end{array}$ \\
\hline Q7_3new1 & $\begin{array}{l}1 \text { if the respondent prefers everyday wine } \\
\text { (flavor) to be dryer; } 0 \text { Otherwise }\end{array}$ \\
\hline
\end{tabular}

The response and explanatory variables used in this model are explained in Table 1. Respondents' demographic characteristics were included from numerous studies relating to marketing aspects of farm produce marketing, farmer-to-consumer direct marketing and consumers expectation like wine testing event and quantified the effects of different factors influencing customers decisions to visit farms in the US (Govindasamy et al. 2014; Surendran et al. 2016; ; Surendran et al. 2016 ${ }^{\text {b }}$.

Table 1: Description of Explanatory Variables 


\begin{tabular}{|c|c|}
\hline Q7_4new1 & $\begin{array}{l}1 \text { if the respondent prefers everyday wine } \\
\text { to be in smaller containers; } 0 \text { Otherwise }\end{array}$ \\
\hline Q7_5new1 & $\begin{array}{l}1 \text { if the respondent prefers everyday wine } \\
\text { with cork closures; } 0 \text { Otherwise }\end{array}$ \\
\hline Q11a & $\begin{array}{l}1 \text { if the respondent consumes wine during } \\
\text { meals; } 0 \text { Otherwise }\end{array}$ \\
\hline Q11b & $\begin{array}{l}1 \text { if the respondent consumes wine when } \\
\text { dining out at a restaurant; } 0 \text { Otherwise }\end{array}$ \\
\hline Q11c & $\begin{array}{l}1 \text { if the respondent consumes wine when } \\
\text { at a party or gathering with family and/or } \\
\text { friends; } 0 \text { Otherwise }\end{array}$ \\
\hline Q11d & $\begin{array}{l}1 \text { if the respondent consumes wine at a bar } \\
\text { or lounge; } 0 \text { Otherwise }\end{array}$ \\
\hline Q11e & $\begin{array}{l}1 \text { if the respondent consumes wine at a } \\
\text { sporting event or concert; } 0 \text { Otherwise }\end{array}$ \\
\hline Q11i & $\begin{array}{l}1 \text { if the respondent consumes wine at the } \\
\text { end of the day to relax; } 0 \text { Otherwise }\end{array}$ \\
\hline Q151 & $\begin{array}{l}1 \text { if the respondent purchases fruit wine; } 0 \\
\text { Otherwise }\end{array}$ \\
\hline
\end{tabular}

gender1 1 if the respondent is male; 0 Otherwise

educ_ $\quad 1$ if the respondent has a bachelor's degree bachelor

fam_inc_ $\quad 1$ if the respondent's earnings are between

new2

fam_inc

new3

job2

job3

job4

job5

job6

marital2

marital3

marital4

or higher; 0 Otherwise

$\$ 76,000$ to $\$ 200,000 ; 0$ Otherwise

1 if the respondent's earnings are $\$ 200,000$

or greater; 0 Otherwise

1 if the respondent is self-employed; 0

Otherwise

1 if the respondent is a student; 0

Otherwise

1 if the respondent is a full-time homemaker; 0 Otherwise

1 if the respondent is unemployed; 0

Otherwise

1 if the respondent is retired; 0 Otherwise

1 if the respondent is single; 0 Otherwise

1 if the respondent is separated or

divorced; 0 Otherwise

1 if the respondent is a widower; 0 Otherwise

\section{RESULTS AND DISCUSSION}

From these 1,246 survey respondents, 152 observations were deleted due to missing values, with the remaining 1,093 observations included in this model. The Akaike Information Criterion (AIC) of the whole model is bigger than the AIC of our first estimation, which means that our model is better after dropping some uninteresting and irrelevant variables. Table 2 shows the logistic regression output. The Margin column shows the marginal effect of each variable. The importance of market segmentation is that it allows a business to conserve money by targeting consumers with specific needs and wants for a particular product (Govindasamy et al. 2018; Lichtenstein et al. 1997; Hofstede et al. 1999; Antreas, 2000; Bruwer \& Li, 2007; Torres \& Kunc, 2016).

Table 2: Logistic Regression Output

\begin{tabular}{|c|c|c|c|c|c|}
\hline Variable & Margin & Std. Err. & z-value & $P>|z|$ & Signif. \\
\hline stateNY & 0.11339 & 0.04409 & 2.5720 & 0.0101 & $* * *$ \\
\hline statePA & -0.01059 & 0.04747 & -0.2231 & 0.8235 & \\
\hline age45to641 & 0.09370 & 0.04026 & 2.3272 & 0.0200 & $* *$ \\
\hline Q1a_F2 & 0.07880 & 0.06903 & 1.1415 & 0.2536 & \\
\hline Q1a_F3 & 0.20119 & 0.06652 & 3.0243 & 0.0025 & $* * *$ \\
\hline Q1a_F4 & 0.17423 & 0.06803 & 2.5613 & 0.0104 & $* * *$ \\
\hline Q1a_F5 & 0.12677 & 0.07747 & 1.6364 & 0.1018 & \\
\hline Q1a_F6 & 0.07690 & 0.08170 & 0.9412 & 0.3466 & \\
\hline Q3b & 0.11219 & 0.03764 & 2.9803 & 0.0029 & $* * *$ \\
\hline Q3e & 0.03902 & 0.03696 & 1.0557 & 0.2911 & \\
\hline Q4a & 0.04403 & 0.04249 & 1.0362 & 0.3001 & \\
\hline $\mathrm{Q} 4 \mathrm{~b}$ & 0.10239 & 0.03884 & 2.6362 & 0.0084 & $* * *$ \\
\hline Q4c & 0.09794 & 0.05660 & 1.7304 & 0.0836 & . \\
\hline Q7_1new1 & 0.09653 & 0.06516 & 1.4815 & 0.1385 & \\
\hline Q7_3new1 & -0.13442 & 0.05452 & -2.4655 & 0.0137 & $* *$ \\
\hline Q7_4new1 & 0.13975 & 0.04349 & 3.2136 & 0.0013 & $* *$ \\
\hline Q7_5new1 & -0.19749 & 0.04753 & -4.1547 & 0.0000 & $* * *$ \\
\hline Q11a & 0.06540 & 0.03834 & 1.7060 & 0.0880 & . \\
\hline Q11b & -0.06189 & 0.03969 & -1.5594 & 0.1189 & \\
\hline Q11c & 0.08557 & 0.04096 & 2.0890 & 0.0367 & $* *$ \\
\hline Q11d & 0.03871 & 0.03605 & 1.0737 & 0.2830 & \\
\hline Q11e & -0.09403 & 0.05247 & -1.7919 & 0.0731 & . \\
\hline Q11i & 0.05807 & 0.03546 & 1.6378 & 0.1015 & \\
\hline Q151 & 0.05431 & 0.03379 & 1.6071 & 0.1080 & \\
\hline $\begin{array}{c}\text { gender1 } \\
\text { educ_ }\end{array}$ & 0.12796 & 0.03611 & 3.5437 & 0.0004 & $* * *$ \\
\hline bachelor & 0.08924 & 0.03530 & 2.5277 & 0.0115 & $* * *$ \\
\hline $\begin{array}{c}\text { fam_inc_ } \\
\text { new2 }\end{array}$ & 0.07916 & 0.03814 & 2.0754 & 0.0379 & $* *$ \\
\hline $\begin{array}{c}\text { fam_inc_ } \\
\text { new3 }\end{array}$ & -0.07604 & 0.09528 & -0.7981 & 0.4248 & \\
\hline job2 & 0.02390 & 0.06386 & 0.3742 & 0.7082 & \\
\hline job3 & 0.03131 & 0.06569 & 0.4766 & 0.6336 & \\
\hline job4 & 0.14372 & 0.05163 & 2.7835 & 0.0054 & $* * *$ \\
\hline job5 & -0.11168 & 0.06049 & -1.8464 & 0.0648 & . \\
\hline
\end{tabular}




\begin{tabular}{cccccc} 
job6 & 0.04000 & 0.08126 & 0.4922 & 0.6225 & \\
marital2 & -0.06861 & 0.03889 & -1.7643 & 0.0777 &. \\
marital3 & 0.02454 & 0.06360 & 0.3859 & 0.6996 & \\
marital4 & 0.09976 & 0.15664 & 0.6368 & 0.5242 & \\
\hline
\end{tabular}

Notes: ${ }^{* *},{ }^{* *}$ Significant at the $5 \%$ and $1 \%$ levels, respectively.

Interpreting the regression output begins with an assessment of the first variable "State" which provides the location where the respondent resides: New Jersey (NJ), New York (NY), or Pennsylvania (PA). From the regression output, people who live in NY are more likely to buy local wine than those who live in NJ. The coefficient of PA is negative, but its p-value is 0.8 , hence there is not enough evidence to prove that PA residents are less likely to buy local wine than NJ residents. The age variable has been re-grouped into two categories. The new variable is named age 45 to 64 with a value of ' 1 ' representing ages from 45 to 64 and a value of ' 0 ' from those age 21 to 44 . As is evident in the regression output, the p-value of age 45 to 64 is 0.02 . Thus, the null hypothesis is rejected soundly at $5 \%$ level with consumers between 45 and 64 years of age being more likely to buy local wine than those who are younger.

Wine consumption frequency is divided into six levels from 1 (drinks daily) to 6 (drinks a few times a year). Level 1 was selected as the reference group, and of the remaining 5 levels, level 3 (drinks about once a week) and level 4 (drinks two to three times a month) being statistically significant compared to the reference group. In addition, levels 3 and 4 have the more significant log odds compared to other levels. Results indicate that people who drink wine about once a week or two to three times a month are more likely to buy local wine than those who drink wine daily. Likewise, those who buy "everyday" wine are more likely to buy local wine. No evidence shows that if consumers buy wine for special occasions, for gifts, or when at a restaurant, that there is any effect on the dependent variable. Consumers who tend to purchase wine to be added to their collections or for consumption later, instead of buying wine for an immediate need, are more likely to buy local wine. To better understand how the two groups differ, the Q7 series variables were examined. Q7 series variables describe the differences in wine price, sweetness, bottle size, closure type, and container material. In our logistic regression model, Q7_1 pertains to price. The result shows that willingness to pay more for everyday wine or to purchase it for special occasion wine doesn't have a significant effect on the decision to BUY local wine. Q7_3 relates to flavor, with consumers who prefer everyday wine to be dryer being more likely to buy local wine. Q7_4 and Q7_5 pertain to bottle size and closure type, respectively. Consumers who prefer to purchase everyday wine in smaller containers are more likely to buy local wine, as are those who prefer to purchase everyday wine with cork closures.

Respondents consume wine for different reasons and on different occasions. Some respondents tend to consume wine with specialty foods, while others tend to drink wine when celebrating holidays. Those who tend to drink wine during meals, when at a party or gathering with family/friends, and at the end of the day to relax, are more likely to purchase local wine. Respondents who tend to consume wine when dining out at a restaurant, at a sporting event or concert are less likely to buy local wine. More than $50 \%$ of consumers indicated that they drink wine when celebrating holidays or other special occasions, but there is not enough evidence to prove its effect on buying decisions. The p-value of the Q15 variable is 0.1077 . It is not small enough to be rejected at the $10 \%$ level, but it is very close. Hence we decided to keep it in the model. Consumers who purchase fruit wine that is not made primarily from grapes are more likely to buy local wine. Gender variable is defined as: male $=1$ and female $=0$. The result shows that males are more likely to buy local wine than females.

The education (educ) variable includes six categories: 1) some high school, 2) high school graduate, 3) some college/technical school, 4) associate degree/ technical school graduate, 5) bachelor's degree, and 6) master's degree or higher. In the first attempt, the categorical education variable was not statistically significant at any level. Therefore, education variable was grouped into two categories: 1 ) those with an education level lower than bachelor's degree and 2) those with a bachelor's degree or higher. Results indicate that a wine consumer with a bachelor's degree or higher is more likely to buy local wine than those with a lower level of education. Annual family income (fam_inc) variable 
was regrouped into three categories: 1) less than $\$ 75,999,2) \$ 76,000$ to $\$ 200,000$, and 3) $\$ 200,000$ or greater. In the regression, we use the second level as the reference group. The result shows that both lower-income people and higher income people are less likely to buy local wine than middle-income people. Level 1 has p-value 0.03, whereas, level 3 has a p-value of 0.1. Employment was categorized into six groups: they are 1) employed by someone else, 2) self-employed, 3) student, 4) full-time homemaker, 5) unemployed and 6) retired. The first category was selected as the reference group. In the results from logistic regression, full-time homemakers are more likely to buy local wine than people employed by someone else. Those unemployed are less likely to buy local wine than people employed by someone else. Regarding marital status, there are four categories: 1) married or in a partnership, 2) single, 3) separated or divorced, 4) widower. The regression results show that single consumers are less likely to buy local wine than those who are married or in a partnership.

\section{CONCLUSION}

Study outcomes show the socio-demographic and behaviors that define consumers in the midAtlantic United States who prefer local wine. For example: New York residents; consumers between 45 and 64 years of age old; males; those with annual household incomes between $\$ 76,000$ and $\$ 200,000$; participants with a bachelor's degree or higher; those who drink wine once a week or two to three times a week; those who purchase wine to consume during different occasions; those who purchase wine for everyday purposes to be consumed in their home; those who purchase wine to be added to their collections or to be consumed at a later time are more likely to buy local wine; those who often drink wine with food, when at a social gathering with family and friends, or at the end of the day to relax, are more likely to purchase local wine. By understanding who, demographically, is a likely local wine buyer, industry stakeholders can target these consumers and, perhaps, obtain a greater return on investment than targeting the general wine drinking population. In addition, by knowing likely local wine drinker's generation, for example, appropriate promotional strategies and communication methods can be developed that have a greater appeal to the targeted consumer. Knowing when consumers drinking local wine, how they treat it after the purchase, and what wine and bottle characteristics are more important than other options can greatly assist the mid-Atlantic wine industry that will be valued by their consumer and hopefully encourage them to increase purchasing.

\section{ACKNOWLEDGMENTS}

This project was supported by the Specialty Crop Research Initiative of the National Institute of Food and Agriculture, USDA, Grant \#2009-51181-06035.

\section{REFERENCES}

Antreas A.D. 2000. Customer Satisfaction Cues To Support Market Segmentation and Explain Switching Behavior, Journal of Business Research, 47(3): 91-207.

Arumugam, S. 2017. Willingness to Pay a Premium for Produce at Direct Marketing Outlets: An Ordered Probit Analysis, SAARC Journal of Agriculture, Bangladesh. SAARC J. Agri., 15(2): 19-30.

Brager, D. 2014. Nielsen presentation on US off-premise wine sales, Wine Market Council $9^{\text {th }}$ Annual Presentation of US Wine Consumer Trends, Santa Rosa, CA, January-2014.

Bruwer, J. and Li, E. 2007. Wine-related lifestyle (WRL) market segmentation: Demographic and behavioral factors. Journal of Wine Research, 18(1): 19-34.

Dodd, T.H., Laverie, D.A., Wilcox, J.F. and Duhan, D.F. 2005. Differential effects of experience, subjective knowledge, and objective knowledge on sources of information used in consumer wine purchasing. Journal of Hospitality $\mathcal{E}$ Tourism Research, 29(1): 3-19.

Fisher, C. 2011. U.S. wineries grow 9\% to 6,785". Wine Business Monthly, 20(5): 70-37.

Govindasamy, R. Surendran, A. and Vellangany, I. 2014. The influence of country-of-origin labeling for lentils on consumer preference: A study with reference to Sri Lanka, The IUP Journal of Marketing Management, 13(3): 31-43.

Govindasamy, R. Surendran, A. You, X. and Vellangany, I. 2015. Willingness to buy organically grown ethnic greens and herbs: A consumers study with reference to the EastCoast Region of United States, Agricultural Economics Research Review, Publisher: Agricultural Economics Research Association, India, 28(2): 213-222.

Govindasamy, R., Surendran, A., Jingkun, Z., Kelley, K.M., and Vellangany, I. 2018. Cluster Analysis of Wine Market Segmentation, A Consumer Based Study In The Mid-Atlantic USA, Economic Affairs-Quarterly Journal of Economics, 63(1): 151-157.

Hofstede, F., Steenkamp, J.B.E.M. and Wedel, M. 1999. International Market Segmentation Based on ConsumerProduct Relations, Journal of Marketing Research, 36(1): 1-17. 
Janeen E. Olsen, Tom Atkin, Liz Thach. and Steve S. Cuellar. 2015. Variety seeking by wine consumers in the southern states of the US, International Journal of Wine Business Research, 27(4): 260-280.

Lichtenstein, Donald, R., Burton, Scot. and Netemeyer, Richard G. 1997. An examination of deal proneness across sales promotion types: A consumer segmentation perspective. Journal of Retailing, 73(2): 283-297.

Nielsen. 2017. State of the Industry - What's Selling. Presentation by Danny Brager at Unified Wine Symposium. Sacramento, CA: Jan. 25, 2017.

Shanken News Daily. 2015. Exclusive: Impact Databank Projects U.S. Wine Market to Expand for $22^{\text {nd }}$ Consecutive Year, December 18, 2015.

http://www.shankennewsdaily.com/index. php/2017/09/18/19216/exclusive-impact-databankprojects-u-s-spirits-market-rise-22nd-consecutive-year/

Surendran, A. and Sekar, C. 2010. An economic analysis of willingness to pay (WTP) for conserving the biodiversity, International Journal of Social Economics, Emerald Group Publishing Limited, United Kingdom, 37(8): 637 - 648.

Surendran, A. Govindasamy, R. and Vellangany, I. 2016. An Analysis of Consumer Preferences for Bed and Breakfast in the Eco-Agritourism Activities, SAARC Journal of Agriculture, 14(2): 162-173.

Surendran, A. Govindasamy, R., You, X. and Vellangany, I. 2016. Country of Origin Labelling (COOL): A Consumer Preference Analysis for Ethnic Greens and Herbs in the East Coast Region of USA, Economic Affairs, 61(4): 1-11.
Torres, Juan Pablo. and Martin H. Kunc. 2016. Market opportunity recognition in the Chilean wine industry: traditional versus relational marketing approaches, 19-33, Received 24 Oct 2014.

U.S. Winery Database 2016. Wine Industry Metrics, Wines Vines Analytics "U.S. Wineries - Count by State Jane 2016". Wines \& Vines.

https://www.winesandvines.com/template. $\mathrm{cfm}$ ? section=widc\&widcDomain=wineries .

Whetstone, K.J., Smith, B.L. and Farley, B. 2011. Fruit Report: October 2011 (N. Y. D. o. A. a. Markets, Trans.) (Vol. No. 975-4-11): United States Department of Agriculture, National Agricultural Statistics Service (USDA-NASS) 2011.

Wine Institute 2014. California Wine Sales Grow 4.4\% by Volume and $6.7 \%$ by Value in the U.S. Press Releases, Wine Institute.

https://www.wineinstitute.org/resources/ pressroom/05192015/.

Wine Institute 2017. World Wine Consumption, 2013-2015, accessed May 9, 2017. http://www.wineinstitute.org/files/ World_Wine_Consumption_by_Country_2015.pdf.

Wines of Province 2016. U.S. Wine Market: Facts \& Figures. http://www.provencewineusa.com/resources/CIVP_ MarketFacts_2016_final.pdf. 
